\title{
Degree of Contribution of Motor and Sensory Scores to Predict Gait Ability in Patients With Incomplete Spinal Cord Injury
}

\author{
Jinkyoo Moon, MD, Junghoon Yu, MD, Jaewoo Choi, MD, MinYoung Kim, MD, PhD, Kyunghoon Min, MD
}

Department of Rehabilitation Medicine, CHA Bundang Medical Center, CHA University, Seongnam, Korea

\begin{abstract}
Objective To identify different contributions of motor and sensory variables for independent ambulation of patients with incomplete spinal cord injury (SCI), and reveal the most significant contributors among the variables.

Methods The retrospective study included 30 patients with incomplete SCI and lesions were confirmed by magnetic resonance imaging. Motor and sensory scores were collected according to the International Standards for Neurological Classification of Spinal Cord Injury. The variables were analyzed by plotting ROC (receiver operating characteristic) curves to estimate their differential contributions for independent walking. The most significant functional determinant was identified through the subsequent logistic regression analysis.

Results Motor and sensory scores were significantly different between the ambulators and non-ambulators. The majority was associated to the function of lower extremities. Calculation of area under ROC curves (AUC) revealed that strength of hip flexor (L2) ( $\mathrm{AUC}=0.905, \mathrm{p}<0.001$ ) and knee extensor (L3) (AUC=0.820, $\mathrm{p}=0.006$ ) contributed the greatest to independent walking. Also, hip flexor strength (L2) was the single most powerful predictor of ambulation by the logistic regression analysis (odds ratio $=6.3, \mathrm{p}=0.049$ ), and the model fit well to the data.

Conclusion The most important potential contributor for independent walking in patients with incomplete SCI is the muscle strength of hip flexors, followed by knee extensors compared with other sensory and motor variables.
\end{abstract}

Keywords Spinal cord injuries, Locomotion, Muscle strength, Sensation, Rehabilitation

\section{INTRODUCTION}

Spinal cord injury (SCI) results in the loss of movement and sensation accompanied by various complications
[1]. Quality of life (QOL) is severely impaired for these patients [2]. Because the ability to walk determines their functional capacity and QOL, restoration of mobility is the most important priority in the rehabilitation setting

Received January 23, 2017; Accepted April 5, 2017

Corresponding author: Kyunghoon Min

Department of Rehabilitation Medicine, CHA Bundang Medical Center, CHA University, Yatap-ro 59, Bundang-gu, Seongnam 13496, Korea. Tel: +8231-780-1892, Fax: +82-31-780-6206, E-mail: minkh@chamc.co.kr

ORCID: Jinkyoo Moon (http://orcid.org/0000-0001-8993-0893); Junghoon Yu (http://orcid.org/0000-0001-6039-5364); Jaewoo Choi (http://orcid. org/0000-0002-4673-0477); MinYoung Kim (http://orcid.org/0000-0001-5481-2985); Kyunghoon Min (http://orcid.org/0000-0003-3357-9795).

(c) This is an open-access article distributed under the terms of the Creative Commons Attribution Non-Commercial License (http://creativecommons.org/ licenses/by-nc/4.0) which permits unrestricted noncommercial use, distribution, and reproduction in any medium, provided the original work is properly cited. Copyright (c) 2017 by Korean Academy of Rehabilitation Medicine 
[3]. Epidemiological studies have indicated an increasing prevalence of patients with incomplete lesions [4]. Since they have a better chance of neurologic improvement the prediction of gait function has been emphasized [5].

Diverse components are involved in ambulation ability after SCI [6-8]. Motor strength is one of the most crucial factors, so muscle strengthening is a principal therapeutic intervention after SCI $[9,10]$. A series of earlier studies indicated that the improvement of muscle strength was related to ambulation outcome. Better than grade 3 recovery of quadriceps strength led to better prognosis of ambulation [11]. Also, gain of leg strength during the first month after SCI is a significant prognostic factor for ambulation [12,13]. In addition, sensory function is reported to be related to ambulation. In case of motor-complete patients, the preservation of pin prick (PP) appreciation is associated with better prognosis for ambulation than the sparing of only light touch (LT) sense at 72 hours and 4 weeks of injury $[14,15]$. In the chronic stage of SCI, the ambulatory capacity was also significantly correlated to recordings of tibial somatosensory evoked potential, although the amount of correlation was less than that of motor scores [16]. A recent cohort study suggested that the preservation of both motor (knee extensor and ankle plantarflexor) and sensory (LT sense on L3 and S1 dermatomes) scores within the first 15 days after injury can predict the independent ambulation 1 year after SCI [7].

Locomotor capacity depends on the preservation of motor and sensory function. Even though many studies suggested that several factors affecting ambulation ability, the most representative contributor for ambulation ability has not been fully understood $[6,8]$. This study aimed to prioritize the motor and sensory variables to expect the ability to walk in patients with incomplete SCI.

\section{MATERIALS AND METHODS}

\section{Subjects}

We retrospectively reviewed the medical records of all patients with SCI admitted to the Department of Rehabilitation Medicine of CHA Bundang Medical Center between March 2014 and February 2015. Criteria for inclusion in the study were (1) incomplete SCI (AIS B, C and D), (2) disease affected period between 2 weeks and 2 years, and (3) neurological level of injury (NLI) that is L2 or higher. Data were collected regardless of the mechanism of injury. Exclusion criteria were brain lesion, pain that hindered activity, cognitive impairment, peripheral neuropathy, and history of surgery involving any limb. Spinal cord lesions were confirmed by magnetic resonance imaging (MRI).

\section{Assessments}

Physical examination was performed for all subjects at admission according to the International Standards for Neurological Classification of Spinal Cord Injury (ISNCSCI) developed by American Spinal Injury Association (ASIA) [17]. Motor grades ranging from 0 to 5 were evaluated in 10 key muscle groups (C5, C6, C7, C8, T1, L2, L3, L4, L5, and S1). Sensory scores including LT and PP senses were also evaluated ( $0=$ absent, $1=$ impaired, $2=$ intact) for whole dermatomes (C2-S4). For each level, higher scores of both sides were included for analysis. ASIA impairment scale (AIS), Lower Extremity Motor Score (LEMS), total PP score, and LT score were determined for all patients.

Patients were allocated into ambulator and nonambulator groups based on Spinal Cord Independence Measure (SCIM) item 12 measuring indoor mobility as scores between 0 to 8 with higher score indicating better ambulation capacity $[18,19]$. Item 12 is useful to assess the ability to walk less than 10 meters. It distinguishes mobility status among total assistant, wheelchair use, walking with aids, and walking without aids, showing excellent reliability and validity in individuals with SCI [20]. We defined non-ambulators as patients unable to walk or require assistance during walking (SCIM item 12 score of 0-3), while any patients who could at least walk with a walking frame or crutch were defined as ambulators (score of 4-8) [7]. The SCIM measurements were assessed within a week after the initial neurologic examination and were performed by blinded physiotherapists who were unaware of the results of the initial examinations.

\section{Statistical analyses}

Initial baseline comparisons for the ambulator and non-ambulator groups included age, gender, etiology, duration of SCI, stage and level of injury, and AIS grade and completeness. Continuous variables were analyzed using Mann-Whitney U-test, but several characteristics were categorized and then compared by Fisher exact test or linear-by-linear association test. Because the vast 
majority of injuries were due to trauma, etiologies were divided into trauma and non-trauma. Duration of injury was categorized into three stages: acute $(<4$ weeks), subacute (4-24 weeks), and chronic ( $>24$ weeks). This was done because the acute phase is usually defined as the first 4 weeks after the injury [21], and the recovery rate rapidly declines within the first 6 months and then plateaus $[12,13]$. Also, we bisected paraplegia patients (T1-T7 and T8-L2) before cross tabulation analysis, considering that their injury levels are distributed more widely than tetraplegia patients.

The Mann-Whitney U-test was used to compare motor and sensory scores between both groups. Receiver operating characteristics (ROC) curves were plotted using motor and sensory variables representing $10 \mathrm{key}$ muscles and whole dermatomes (C2-S4), respectively, to discriminate between ambulators and non-ambulators. By calculating of the area under ROC curves (AUC), the discriminative accuracy of each physical exam was quantified, and the priority of each variable for ambulation was estimated. Generally, an AUC of 0.5 suggests no discrimination, 0.7 to 0.8 is considered acceptable, 0.8 to 0.9 is considered excellent, and more than 0.9 is considered outstanding discriminatory power [22].

Motor and sensory scores were included for the logistic regression analysis. Because the number of motor and

Table 1. Baseline demographics and SCI characteristics of the participants $(n=30)$

\begin{tabular}{|c|c|c|c|}
\hline & $\begin{array}{c}\text { Ambulator }{ }^{\text {a }} \\
(\mathbf{n}=9)\end{array}$ & $\begin{array}{c}\text { Non-ambulator }{ }^{b)} \\
(n=21)\end{array}$ & p-value \\
\hline $\operatorname{Age}(\mathrm{yr})^{\mathrm{c})}$ & $50.0(7.50)$ & $55.0(10.00)$ & 0.389 \\
\hline Gender $^{\mathrm{d})}$ & & & 1.000 \\
\hline Male & $5(55.6)$ & $12(57.1)$ & \\
\hline Female & $4(44.4)$ & $9(42.9)$ & \\
\hline Etiology ${ }^{\mathrm{d})}$ & & & 0.640 \\
\hline Trauma & $6(66.7)$ & $17(81.0)$ & \\
\hline Non-trauma ${ }^{\mathrm{e})}$ & $3(33.3)$ & $4(19.0)$ & \\
\hline Duration of SCI (wk) & $48.0(38.25)$ & $40.0(59.75)$ & 0.803 \\
\hline Stage of injury ${ }^{\mathrm{f})}$ & & & 0.911 \\
\hline Acute (2-4 wk) & $3(33.3)$ & $8(38.1)$ & \\
\hline Subacute (4-24 wk) & $5(55.6)$ & $9(42.9)$ & \\
\hline Chronic (>24 wk) & $1(11.1)$ & $4(19.0)$ & \\
\hline Level of injury ${ }^{\mathrm{f})}$ & & & 0.240 \\
\hline Tetraplegia & $4(44.4)$ & $14(66.7)$ & \\
\hline Paraplegia (T1-T7) & $1(11.1)$ & $2(9.5)$ & \\
\hline Paraplegia (T8-) & $4(44.4)$ & $5(23.8)$ & \\
\hline AIS grade $\mathrm{f}^{\mathrm{f})}$ & & & $0.014^{*}$ \\
\hline $\mathrm{B}$ & $0(0)$ & $3(14.3)$ & \\
\hline $\mathrm{C}$ & $0(0)$ & $8(38.1)$ & \\
\hline $\mathrm{D}$ & $9(100)$ & $10(47.6)$ & \\
\hline Motor completeness ${ }^{\mathrm{d})}$ & & & 0.534 \\
\hline Motor complete & $0(0)$ & $3(14.3)$ & \\
\hline Motor incomplete & $9(100)$ & $18(85.7)$ & \\
\hline
\end{tabular}

Values are presented as median (interquartile range) or number of cases (\%).

SCI, spinal cord injury; AIS, American Spinal Injury Association (ASIA) impairment scale.

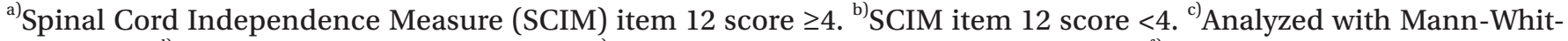
ney U-test. ${ }^{\mathrm{d})}$ Analyzed with Fisher exact test. ${ }^{\mathrm{e})}$ Tumor, inflammation, or spinal stenosis. ${ }^{\mathrm{f})}$ Analyzed with linear-by-linear association test.

${ }^{*} \mathrm{p}<0.05$. 
sensory variables was large (PP 28, LT 28, key motor 10), variables with significant inter-group difference were screened to find out meaningful differentiators and were included for the logistic regression analysis. Independent analysis was done with every single variable to reduce noisy influences from many parameters tested. The cutoff $\mathrm{p}$-value was stringent $(\mathrm{p}<0.01)$ to simplify variables and avoid type I errors, so only candidate variables with high statistical significance were collected and subsequently included in final logistic regression analysis. Goodness-of-fit of the model was assessed by HosmerLemeshow test [23]. All data were analyzed using SPSS Statistics ver. 21 for Windows (IBM, Armonk, NY, USA).

\section{RESULTS}

Thirty patients (17 males and 13 females) with incomplete SCI were finally enrolled (Table 1). They comprised 9 ambulators and 21 non-ambulators. There were no significant baseline differences between these groups in age, gender, etiology of SCI, neurological injury level, and the duration or stage of SCI. AIS grade, as expected, was significantly different between the groups. However, both groups did not show significant difference in the distribution of patients with motor complete lesion, AIS B (Table 1).

All lower extremity motor scores were significantly different between the ambulators and non-ambulators (Table 2). Sensory scores of lower extremity also showed a significant difference (L5 or above for LT, and L4 or above for PP) (Table 3). However, in case of upper extremities, only motor scores of C7, C8 and T1 were significantly different, and all sensory scores did not show a significant difference. The ambulators showed significantly higher LEMS, while total PP and LT scores did not differ statistically significantly between groups.

ROC analysis was performed for 68 variables including LEMS, and total PP and LT scores. The selected ROC curves are presented in Fig. 1, and areas under significant ROC curves from motor and sensory variables are presented in Table 4. Thirteen variables were statistically significant $(p<0.05)$. Among them, nine variables were associated with lower extremity function, and only a few motor scores were identified as meaningful contributors that accurately discriminated the ambulators from non-ambulators. The motor score of L2 level (hip flexor) showed outstanding accuracy $(A U C=0.905, p<0.001)$,
Table 2. Motor scores at each root level of patients according to ISNCSCI

\begin{tabular}{lccc}
\hline \multirow{2}{*}{ Root level } & \multicolumn{2}{c}{ Muscle strength $^{\text {a) }}$} & \multirow{2}{*}{ p-value } \\
\cline { 2 - 3 } & Ambulator & Non-ambulator & \\
\hline C5 & $5(0.75)$ & $3(1.00)$ & 0.135 \\
C6 & $5(1.00)$ & $2(1.50)$ & 0.052 \\
C7 & $5(1.00)$ & $3(1.50)$ & $0.036^{*}$ \\
C8 & $5(1.00)$ & $2(2.00)$ & $0.042^{*}$ \\
\hline T1 & $5(1.00)$ & $2(2.00)$ & $0.017^{*}$ \\
\hline L2 & $4(0.25)$ & $2(1.00)$ & $<0.001^{* * *}$ \\
L3 & $4(0.00)$ & $3(1.25)$ & $0.004^{* *}$ \\
L4 & $4(0.50)$ & $3(1.50)$ & $0.019^{*}$ \\
\hline L5 & $4(0.50)$ & $2(1.25)$ & $0.014^{*}$ \\
\hline S1 & $4(0.50)$ & $3(1.50)$ & $0.043^{*}$ \\
\hline LEMS & $34(4.75)$ & $24(12.50)$ & $0.018^{\text {b) }}$ \\
\hline
\end{tabular}

Values are presented as median (interquartile range).

ISNCSCI, International Standards for Neurological Classification of Spinal Cord Injury; LEMS, Lower Extremity Motor Score.

${ }^{a)}$ Muscle strength graded from 0 (absent) to 5 (normal) using a 6-point scale. ${ }^{\text {b) }}$ Sum of motor scores from bilateral lower extremities.

${ }^{*} \mathrm{p}<0.05,{ }^{* *} \mathrm{p}<0.01,{ }^{* * *} \mathrm{p}<0.001$ by Mann-Whitney U-test.

followed by the motor score of L3 level (knee extensor) with excellent accuracy (AUC=0.820, $\mathrm{p}=0.006$ ). AUC from strength of hip flexor and knee extensor were even higher than that of LEMS (AUC $=0.775, p=0.019$ ), which is generally accepted as an important indicator of gait function in patients with SCI [24]. In addition, the cutoff motor score with $100 \%$ sensitivity for both variables was 2.5 , indicating that it would be difficult to walk independently if strength of hip flexor or knee extensor was 'poor' or worse. Although other variables, such as sensory scores for L2 and L3 dermatomes and motor score for L5 (ankle dorsiflexor), showed relatively high AUC with statistical significance, they were $<0.8$, indicative of only moderate accuracy for discrimination. Among the sensory scores with statistical significance, PP sense was ranked higher in common than LT sense.

Next, logistic regression analysis was performed. All variables identified as having significant difference between both groups including several motor scores (from C7 to S1), LT sensory scores (from T12 to L5), and PP sensory scores (from T10 to L4) were analyzed. Independent logistic regression analysis for each variable revealed 
Table 3. Sensory scores at each root level of patients according to ISNCSCI

\begin{tabular}{|c|c|c|c|c|c|c|}
\hline \multirow{2}{*}{ Root level } & \multicolumn{2}{|c|}{ Light touch $^{\text {a) }}$} & \multirow{2}{*}{ p-value } & \multicolumn{2}{|c|}{ Pin prick $^{\mathrm{b})}$} & \multirow{2}{*}{ p-value } \\
\hline & Ambulator & Non-ambulator & & Ambulator & Non-ambulator & \\
\hline $\mathrm{C} 2$ & $2(0.00)$ & $2(0.00)$ & 1.000 & $2(0.00)$ & $2(0.00)$ & 1.000 \\
\hline $\mathrm{C} 3$ & $2(0.00)$ & $2(0.00)$ & 0.127 & $2(0.00)$ & $2(0.00)$ & 1.000 \\
\hline $\mathrm{C} 4$ & $2(0.00)$ & $2(0.00)$ & 0.530 & $2(0.00)$ & $2(0.00)$ & 0.896 \\
\hline C5 & $2(0.25)$ & $2(0.50)$ & 0.406 & $2(0.25)$ & $2(0.50)$ & 0.187 \\
\hline C6 & $2(0.25)$ & $1(0.50)$ & 0.116 & $2(0.25)$ & $1(0.50)$ & 0.107 \\
\hline $\mathrm{C} 7$ & $2(0.25)$ & $1(0.50)$ & 0.116 & $2(0.50)$ & $1(0.50)$ & 0.155 \\
\hline $\mathrm{C} 8$ & $2(0.50)$ & $1(0.50)$ & 0.195 & $2(0.50)$ & $1(0.50)$ & 0.155 \\
\hline $\mathrm{T} 1$ & $2(0.50)$ & $1(0.50)$ & 0.195 & $2(0.50)$ & $1(0.50)$ & 0.155 \\
\hline $\mathrm{T} 2$ & $2(0.50)$ & $1(0.50)$ & 0.195 & $2(0.50)$ & $1(0.50)$ & 0.155 \\
\hline T3 & $2(0.50)$ & $1(0.50)$ & 0.128 & $2(0.50)$ & $1(0.50)$ & 0.102 \\
\hline $\mathrm{T} 4$ & $2(0.50)$ & $1(0.50)$ & 0.298 & $2(0.50)$ & $1(0.75)$ & 0.128 \\
\hline T5 & $2(0.50)$ & $1(0.50)$ & 0.175 & $2(0.50)$ & $1(0.75)$ & 0.128 \\
\hline T6 & $2(0.50)$ & $1(0.50)$ & 0.175 & $2(0.50)$ & $1(0.75)$ & 0.128 \\
\hline $\mathrm{T} 7$ & $2(0.50)$ & $1(0.50)$ & 0.175 & $2(0.50)$ & $1(0.75)$ & 0.128 \\
\hline $\mathrm{T} 8$ & $2(0.50)$ & $1(0.50)$ & 0.111 & $2(0.50)$ & $1(0.75)$ & 0.081 \\
\hline T9 & $2(0.50)$ & $1(0.50)$ & 0.111 & $2(0.50)$ & $1(0.75)$ & 0.081 \\
\hline $\mathrm{T} 10$ & $2(0.50)$ & $1(0.25)$ & 0.065 & $2(0.50)$ & $1(0.75)$ & $0.040^{*}$ \\
\hline T11 & $2(0.50)$ & $1(0.25)$ & 0.065 & $2(0.50)$ & $1(0.75)$ & $0.040^{*}$ \\
\hline $\mathrm{T} 12$ & $2(0.50)$ & $1(0.00)$ & $0.035^{*}$ & $2(0.50)$ & $1(0.50)$ & $0.022^{*}$ \\
\hline L1 & $2(0.50)$ & $1(0.00)$ & $0.007^{* *}$ & $2(0.50)$ & $1(0.50)$ & $0.011^{*}$ \\
\hline L2 & $2(0.50)$ & $1(0.00)$ & $0.006^{* *}$ & $2(0.50)$ & $1(0.50)$ & $0.005^{* *}$ \\
\hline L3 & $1(0.50)$ & $1(0.00)$ & $0.020^{*}$ & $1(0.50)$ & $1(0.50)$ & $0.006^{* *}$ \\
\hline L4 & $1(0.50)$ & $1(0.00)$ & $0.020^{*}$ & $1(0.50)$ & $1(0.50)$ & $0.028^{*}$ \\
\hline L5 & $1(0.50)$ & $1(0.00)$ & $0.023^{*}$ & $1(0.50)$ & $1(0.50)$ & 0.064 \\
\hline S1 & $1(0.50)$ & $1(0.00)$ & 0.104 & $1(0.75)$ & $1(0.50)$ & 0.195 \\
\hline S2 & $1(0.50)$ & $1(0.00)$ & 0.175 & $1(0.75)$ & $1(0.50)$ & 0.220 \\
\hline S3 & $1.5(0.25)$ & $1(0.00)$ & 0.355 & $1(0.50)$ & $1(0.50)$ & 0.373 \\
\hline S4 & $1.5(0.50)$ & $1(0.00)$ & 0.555 & $1(0.75)$ & $1(0.50)$ & 0.573 \\
\hline Total $^{\mathrm{c})}$ & $92(18.25)$ & $64(13.50)$ & 0.217 & $92(18.75)$ & $62(18.75)$ & 0.187 \\
\hline
\end{tabular}

Values are presented as median (interquartile range).

ISNCSCI, International Standards for Neurological Classification of Spinal Cord Injury.

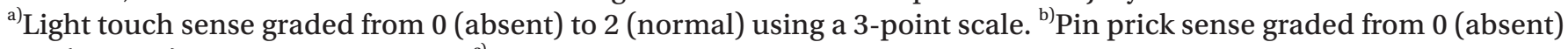
to 2 (normal) using a 3-point scale. ${ }^{\mathrm{c}}$ Sum of light touch or pin prick scores of all dermatomes.

${ }^{*} \mathrm{p}<0.05,{ }^{* *} \mathrm{p}<0.01$ by Mann-Whitney U-test.

a few functional components with high statistical significance $(\mathrm{p}<0.01)$. These were collectively used for the final logistic regression analysis. The most statistically significant variable was motor score of the L2 level. The Hosmer-Lemeshow test was performed as a goodness-offit statistic, and the chi-square was 1.422 with 7 degrees of freedom, adopting the null hypothesis. The model was correctly able to classify $90.5 \%$ of those who did ambulate independently and $66.7 \%$ of those who did not, for an overall success rate of $83.3 \%$. Thus, it would be possible to suggest the significance of hip flexor strength for prediction of ambulation ability $(\mathrm{p}=0.049$, odds ratio $=6.335)$ (Table 5). 


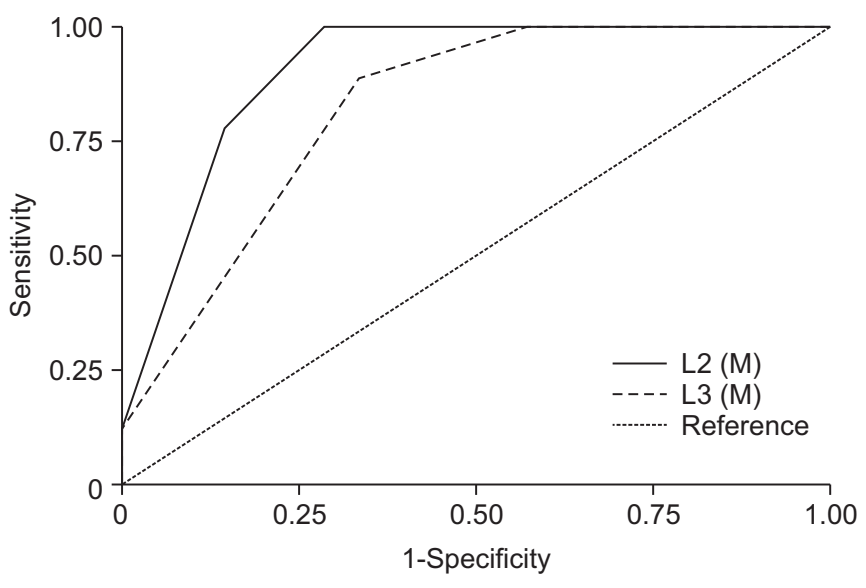

Fig. 1. Receiver operating characteristic (ROC) curves of selected predictors. A total of 69 motor and sensory variables including LEMS, total LT, and PP scores were analyzed to identify their performance to discriminate the ambulators and non-ambulators by ROC curves. Two predictors showed AUC over 0.8 indicating excellent discriminatory accuracy; motor scores of hip flexor (L2, AUC $=0.905)$ and knee extensor (L3, AUC=0.820). $\mathrm{M}$, muscle strength; AUC, area under ROC curve.

\section{DISCUSSION}

Locomotion is most often affected in people with SCI. Decreased mobility is associated with low QOL following SCI $[25,26]$. Improving mobility or the ability to ambulate in an energy-efficient manner may improve health-related QOL in persons with SCI [27]. Several components are regarded as important determinants of walking such as balance, spasticity, age, and strength $[8,28]$. Among them, lower extremity strength is the most widely studied factor in SCI patients in relation to both functional independence and gait [9]. However, the degree of different contribution of each functional component is still unclear, even though ambulation is an integration of motor and sensory functions originating from multiple spinal cord levels.

The aim of this study was to identify relative importance of the various substantial contributors for ambulation among the motor and sensory scores assessed according to ISNCSCI in patients with incomplete SCI. Predictably, most of the lower extremity scores were significantly higher in independent ambulators than in non-ambulators, which might have different contributions for gait ability. We assumed that the AUC of each variable is able to reflect the relative degree of contribution for indepen-
Table 4. AUC of significant predictors for discrimination of ambulation ability

\begin{tabular}{|cccc}
\hline Predictor & AUC & 95\% CI & p-value \\
\hline L2 (M) & 0.905 & $0.782-1.000$ & $<0.001^{* * *}$ \\
\hline L3 (M) & 0.820 & $0.671-0.969$ & $0.006^{* *}$ \\
\hline L2 (PP) & 0.794 & $0.620-0.968$ & $0.012^{*}$ \\
\hline L5 (M) & 0.778 & $0.610-0.946$ & $0.018^{*}$ \\
\hline L3 (PP) & 0.778 & $0.597-0.958$ & $0.018^{*}$ \\
\hline L2 (LT) & 0.772 & $0.584-0.961$ & $0.020^{*}$ \\
\hline L1 (PP) & 0.770 & $0.591-0.949$ & $0.021^{*}$ \\
\hline T1(M) & 0.770 & $0.605-0.934$ & $0.021^{*}$ \\
\hline L4 (M) & 0.762 & $0.592-0.931$ & $0.025^{*}$ \\
\hline L1 (LT) & 0.762 & $0.566-0.958$ & $0.025^{*}$ \\
\hline T12 (PP) & 0.746 & $0.563-0.929$ & $0.035^{*}$ \\
\hline C7 (M) & 0.735 & $0.559-0.912$ & $0.044^{*}$ \\
\hline C8 (M) & 0.730 & $0.553-0.908$ & $0.049^{*}$ \\
\hline LEMS & 0.775 & $0.605-0.945$ & $0.019^{*}$ \\
\hline LT total & 0.643 & $0.418-0.868$ & 0.222 \\
\hline PP total & 0.653 & $0.434-0.873$ & 0.189 \\
\hline A
\end{tabular}

AUC, area under ROC curve; ROC, receiver operating characteristic; $\mathrm{CI}$, confidence interval; $\mathrm{M}$, muscle strength; PP, pin prick sense; LT, light touch sense; LEMS, Lower Extremity Motor Score.

${ }^{*} \mathrm{p}<0.05,{ }^{* *} \mathrm{p}<0.01$.

dent gait.

ROC analysis revealed that the discriminating power of each motor and sensory score differed. The motor scores of hip flexor, followed by knee extensor showed remarkable accuracy. Even though the absolute size of contribution for gait is impossible to determine from AUCs, hip flexor and knee extensor AUCs were higher than that of LEMS, indicating their relative importance. Also, the strength of hip flexor was the single most relevant factor to predict independent ambulation according to the logistic regression analysis accompanying of overall success rate of $\mathbf{8 3 . 3 \%}$. On the other hand, sensory scores seemed to have relatively weak strength to classify the ambulators. Several sensory scores including PP (L2, L3, L1) followed by LT sense (L2, L1) showed an acceptable level of contribution.

We found only one study that ranked individual contribution of each muscle strength in SCI patients [29]. Although that study focused on only motor scores of lower extremity with small sample size, it revealed the importance of several proximal leg muscles including 
Table 5. Logistic regression analysis for functional components predicting ambulation ability in patients with spinal cord injury

\begin{tabular}{|c|c|c|c|c|c|}
\hline & Wald $\chi^{2}$ & $x^{2}$ & df & Odds ratio & p-value \\
\hline \multicolumn{6}{|l|}{ Predictor } \\
\hline Ll (PP) & $<0.001$ & & 1 & 7.284 & NS \\
\hline L2 (PP) & $<0.001$ & & 1 & $<0.001$ & NS \\
\hline L2 (LT) & $<0.001$ & & 1 & 6.335 & NS \\
\hline Ll (LT) & $<0.001$ & & 1 & $<0.001$ & NS \\
\hline L3 (PP) & 0.915 & & 1 & 6.704 & NS \\
\hline L2 (M) & 3.863 & & 1 & 6.335 & $0.049^{*}$ \\
\hline \multicolumn{6}{|l|}{ Goodness-of-fit test } \\
\hline Hosmer-Lemeshow & - & 1.422 & 7 & - & 0.985 \\
\hline
\end{tabular}

PP, pin prick sense; LT, light touch sense; df, degrees of freedom; M, muscle strength; NS, not significant. ${ }^{*} \mathrm{p}<0.05$.

hip flexors, hip extensors, and hip abductors for walking performance. Other relevant studies assessed diverse neurological variables to determine their predictive values for walking capacity. Although each study regarded different factors as the representative for ambulation, some studies were consistent with our findings. In some old studies, the strength of hip flexors [30] and quadriceps femoris [11] were regarded as important factors. A recent large longitudinal cohort study demonstrated that preservation of quadriceps femoris and gastrocnemius, in terms of motor function, has high predictive value for outcome of ambulation in SCI patients [7].

These consistent observations for relationships between ambulation ability and strength of hip flexor or knee extensor can be explained by several studies. Basically, ankle plantar flexors are a crucial contributor to swing initiation [31]. However, iliopsoas muscle operation, which is responsible for accelerating the trail limb forward acting on terminal stance and early swing, increases much more than that of gastrocnemius as gait speed increases [32]. This means that hip flexors are likely an important compensatory mechanism for decreased plantarflexor output at higher walking speeds. In this regard, our finding can be interpreted as indicating that SCI patients with more preserved hip flexor strength of hip flexor may ultimately have better ambulation because weakness in the distal musculature innervated by lower root levels is compensated for by proximal muscles. Indeed, in a pathologic population whose gait speed is limited due to impaired ankle plantarflexors, the hip flexors play an important role in compensation for slow walking speed [33]. Moreover, the hip flexors, such as rectus femoris and iliopsoas, are cardinal in restoring a normal gait pattern in below-knee amputees [34]. Another significant classifier in the present study was knee extensor strength. During gait a high-frequency impulsive load is applied repeatedly at heel strike ranges from 0.5 to 1.25 times body weight, and knee extensors may provide the critical mechanism for this most demanding task by attenuating the gravity effect $[35,36]$. Our findings about knee extensor would be possible to be considered also in this point of view.

Beside to motor aspects, our findings supported some studies, which revealed that SCI patients with sparing of PP sense, rather than LT sense, showed better ambulation outcome $[14,15]$. In this study, discrimination of independent ambulators by PP sense preservation (L2 and L3) was more accurate than by LT sense preservation (L2, L3, and L4). The findings might be associated with the closer proximity of the spinothalamic tract (PP) to the lateral corticospinal tract (motor) than that of dorsal column pathway (LT) [37].

There are several limitations in our study. First, the criteria for patient selection included a broad range of disease-affected period. Potential of functional attainment declines according to the time course of disease, though the period was not different between the ambulator and non-ambulator groups and restricted to between 2 weeks and 2 years. However, our study was a cross-sectional analysis for graded effect of neurological variables on ambulation at the time of evaluation, not for future recovery potential affected by the time of evaluation from 
onset and subsequent changes with time. Second, even though trauma was the main cause of injury, the etiology for spinal cord injury was not completely homogeneous and included trauma, tumor, inflammation, and spinal stenosis. It would be possible that taking into account different etiologies may generate different results. However, the etiology of both groups was not statistically different from each other, and their composition was very similar to that of a recent SCI population in South Korea [38]. Third, the dichotomous outcome from SCIM item 12 adopted in this study is limited as the assessment does not provide information of various aspects of locomotor ability. The last limitation is the use of ROC analysis on ordinal scale with small number of categories. Discrete ROC curves can be generated by test-result data collected on graded (rather than binary) ordinal scale. Generally ordinal scale with 4 to 7 categories has been used because fewer categories may lead the underestimation of AUC or degeneration of the curve [39]. The ISNCSCI sensory score is a 3-point ordinal $(0,1,2)$ scale, so our results related to sensory variables should be interpreted with caution. The reason why ROC analysis was adopted to rank contribution of even sensory score is based on its advantageous characteristics. Various diagnostic exams on the same subjects can be compared simultaneously in single ROC space. As well, no structural assumptions are made about the form of the plot, and the underlying distributions of the outcomes for the both groups do not need to be specified [40]. These specific advantages described above were complementarily matched with our data set, and were mostly appropriate to discern potential answers to our question, despite the statistical limitation.

In conclusion, the strength of hip flexor and knee extensor may be the most important factors of SCI patients for independent gait. These findings may provide information for determination of rehabilitation goal setting regarding ambulation. Further studies with well controlled larger sample sizes using robust statistical analysis are required to confirm our findings and to elucidate the role of sensory function. Also, longitudinal cohort studies to identify the relationship between recovery of walking ability and improvement of each sensorimotor component are warranted.

\section{CONFLICT OF INTEREST}

No potential conflict of interest relevant to this article was reported.

\section{REFERENCES}

1. Adriaansen JJ, van Asbeck FW, Lindeman E, van der Woude LH, de Groot S, Post MW. Secondary health conditions in persons with a spinal cord injury for at least 10 years: design of a comprehensive long-term cross-sectional study. Disabil Rehabil 2013;35:110410.

2. McDonald JW, Sadowsky C. Spinal-cord injury. Lancet 2002;359:417-25.

3. Ditunno PL, Patrick M, Stineman M, Ditunno JF. Who wants to walk? Preferences for recovery after SCI: a longitudinal and cross-sectional study. Spinal Cord 2008;46:500-6.

4. Pagliacci MC, Celani MG, Spizzichino L, Zampolini M, Aito S, Citterio A, et al. Spinal cord lesion management in Italy: a 2-year survey. Spinal Cord 2003;41: 620-8.

5. Fawcett JW, Curt A, Steeves JD, Coleman WP, Tuszynski MH, Lammertse D, et al. Guidelines for the conduct of clinical trials for spinal cord injury as developed by the ICCP panel: spontaneous recovery after spinal cord injury and statistical power needed for therapeutic clinical trials. Spinal Cord 2007;45:190-205.

6. Scivoletto G, Tamburella F, Laurenza L, Torre M, Molinari M. Who is going to walk? A review of the factors influencing walking recovery after spinal cord injury. Front Hum Neurosci 2014;8:141.

7. van Middendorp JJ, Hosman AJ, Donders AR, Pouw MH, Ditunno JF Jr, Curt A, et al. A clinical prediction rule for ambulation outcomes after traumatic spinal cord injury: a longitudinal cohort study. Lancet 2011; 377:1004-10.

8. Scivoletto G, Romanelli A, Mariotti A, Marinucci D, Tamburella F, Mammone A, et al. Clinical factors that affect walking level and performance in chronic spinal cord lesion patients. Spine (Phila Pa 1976) 2008;33: 259-64.

9. Frost FS. Role of rehabilitation after spinal cord injury. Urol Clin North Am 1993;20:549-59.

10. Perry J. Rehabilitation of the neurologically disabled 
patient: principles, practice, and scientific basis. J Neurosurg 1983;58:799-816.

11. Crozier KS, Cheng LL, Graziani V, Zorn G, Herbison G, Ditunno JF Jr. Spinal cord injury: prognosis for ambulation based on quadriceps recovery. Paraplegia 1992; 30:762-7.

12. Waters RL, Adkins RH, Yakura JS, Sie I. Motor and sensory recovery following incomplete tetraplegia. Arch Phys Med Rehabil 1994;75:306-11.

13. Waters RL, Adkins RH, Yakura JS, Sie I. Motor and sensory recovery following incomplete paraplegia. Arch Phys Med Rehabil 1994;75:67-72.

14. Crozier KS, Graziani V, Ditunno JF Jr, Herbison GJ. Spinal cord injury: prognosis for ambulation based on sensory examination in patients who are initially motor complete. Arch Phys Med Rehabil 1991;72:119-21.

15. Oleson CV, Burns AS, Ditunno JF, Geisler FH, Coleman WP. Prognostic value of pinprick preservation in motor complete, sensory incomplete spinal cord injury. Arch Phys Med Rehabil 2005;86:988-92.

16. Curt A, Dietz V. Ambulatory capacity in spinal cord injury: significance of somatosensory evoked potentials and ASIA protocol in predicting outcome. Arch Phys Med Rehabil 1997;78:39-43.

17. Kirshblum SC, Burns SP, Biering-Sorensen F, Donovan $\mathrm{W}$, Graves DE, Jha A, et al. International standards for neurological classification of spinal cord injury (revised 2011). J Spinal Cord Med 2011;34:535-46.

18. Catz A, Itzkovich M. Spinal Cord Independence Measure: comprehensive ability rating scale for the spinal cord lesion patient. J Rehabil Res Dev 2007;44:65-8.

19. Catz A, Itzkovich M, Tamir A, Philo O, Steinberg F, Ring H, et al. SCIM: spinal cord independence measure (version II): sensitivity to functional changes. Harefuah 2002;141:1025-31.

20. Catz A, Itzkovich M, Tesio L, Biering-Sorensen F, Weeks C, Laramee MT, et al. A multicenter international study on the Spinal Cord Independence Measure, version III: Rasch psychometric validation. Spinal Cord 2007;45:275-91.

21. Hagen EM. Acute complications of spinal cord injuries. World J Orthop 2015;6:17-23.

22. Hosmer DW, Lemeshow S. Applied logistic regression. 2nd ed. New York: John Wiley \& Sons; 2004.

23. Hosmer DW, Lemesbow S. Goodness of fit tests for the multiple logistic regression model. Commun Stat
Theory Methods 1980;9:1043-69.

24. Waters RL, Adkins R, Yakura J, Vigil D. Prediction of ambulatory performance based on motor scores derived from standards of the American Spinal Injury Association. Arch Phys Med Rehabil 1994;75:756-60.

25. Putzke JD, Richards JS, Hicken BL, DeVivo MJ. Predictors of life satisfaction: a spinal cord injury cohort study. Arch Phys Med Rehabil 2002;83:555-61.

26. Noreau L, Shephard RJ. Spinal cord injury, exercise and quality of life. Sports Med 1995;20:226-50.

27. Jain NB, Sullivan M, Kazis LE, Tun CG, Garshick E. Factors associated with health-related quality of life in chronic spinal cord injury. Am J Phys Med Rehabil 2007;86:387-96.

28. Barbeau H, Nadeau S, Garneau C. Physical determinants, emerging concepts, and training approaches in gait of individuals with spinal cord injury. J Neurotrauma 2006;23:571-85.

29. Kim CM, Eng JJ, Whittaker MW. Level walking and ambulatory capacity in persons with incomplete spinal cord injury: relationship with muscle strength. Spinal Cord 2004;42:156-62.

30. Hussey RW, Stauffer ES. Spinal cord injury: requirements for ambulation. Arch Phys Med Rehabil 1973; 54:544-7.

31. Neptune RR, Kautz SA, Zajac FE. Contributions of the individual ankle plantar flexors to support, forward progression and swing initiation during walking. J Biomech 2001;34:1387-98.

32. Neptune RR, Sasaki K, Kautz SA. The effect of walking speed on muscle function and mechanical energetics. Gait Posture 2008;28:135-43.

33. Nadeau S, Gravel D, Arsenault AB, Bourbonnais D. Plantarflexor weakness as a limiting factor of gait speed in stroke subjects and the compensating role of hip flexors. Clin Biomech (Bristol, Avon) 1999;14:12535.

34.Zmitrewicz RJ, Neptune RR, Sasaki K. Mechanical energetic contributions from individual muscles and elastic prosthetic feet during symmetric unilateral transtibial amputee walking: a theoretical study. J Biomech 2007;40:1824-31.

35. Simon SR, Paul IL, Mansour J, Munro M, Abernethy PJ, Radin EL. Peak dynamic force in human gait. J Biomech 1981;14:817-22.

36. Light LH, McLellan GE, Klenerman L. Skeletal tran- 
sients on heel strike in normal walking with different footwear. J Biomech 1980;13:477-80.

37. Katoh S, el Masry WS. Motor recovery of patients presenting with motor paralysis and sensory sparing following cervical spinal cord injuries. Paraplegia 1995; 33:506-9.

38. Han ZA, Lee BS, Kim W, Lee SJ, Im HJ, Kim C, et al. People with spinal cord injury in Korea. Am J Phys
Med Rehabil 2017;96(2 Suppl 1):S83-5.

39. Beutel J, Kundel HL, Van Metter RL. Handbook of medical imaging: physics and psychophysics. Bellingham: SPIE Press; 2000.

40. Hsieh F, Turnbull BW. Nonparametric and semiparametric estimation of the receiver operating characteristic curve. Ann Stat 1996;24:25-40. 